\title{
Trends in online media relations: Web-based corporate press rooms in leading international companies
}

\author{
González-Herrero Alfonso $^{\mathrm{a}, *}$, Ruiz de Valbuena Miguel ${ }^{\mathrm{b}, 1}$ \\ ${ }^{a}$ Department of Communications, IBM Spain, Calle Santa Hortensia 26-28, Madrid 28002, Spain \\ b Department of Communications, IBM Spain, Calle Santa Hortensia 26-28, Madrid 28002, Spain
}

Received 7 February 2006; received in revised form 4 April 2006; accepted 29 May 2006

\begin{abstract}
An analysis of 120 corporate websites from Denmark, France, Germany, Norway, Singapore, Spain, the United Kingdom and the United States reveals, for the first time, international results about the implementation and use of virtual press rooms. This article shows the importance that large international companies attribute to Web-based media centers to achieve organizational objectives and to meet journalists' demands for information and audiovisual resources. The study also shows, however, that most press rooms are far from being complete, efficient, easy-to-use, reliable and updated on a daily basis. In fact, there is not a single country from those analyzed that consistently stands out from the rest. In most of them, good results in certain areas coexist with significant shortcomings in others, resulting in some cases in poor press rooms that may not achieve the desired public relations objectives. (C) 2006 Elsevier Inc. All rights reserved.
\end{abstract}

Keywords: Online; Media relations; Web; Press room; Internet

\section{Introduction}

Over the last decade, the Internet has remarkably changed the way in which companies and institutions communicate and interact with their audiences. The same is true about how organizations communicate with the news media, as well as how these media conduct their work nowadays.

For corporate communications, Internet technologies (including not only external websites, but also corporate intranets) offer lots of possibilities. Initially, the exchange of text messages through e-mail was a significant step forward. Later, the possibility of transmitting images and sounds through the Internet encouraged thousands of companies to launch their own websites, even when their reach and the value they could offer (both from a sales and information perspective) was still very limited.

With new tools such as blogs, wikis or RSS technologies becoming increasingly more popular recently, the idea of the Internet as the key tool for sharing knowledge, ideas or corporate information is growing. And although the impact of this new reality on corporate communications in companies and organizations is not still well defined, it is obvious that the Internet is a rapidly changing environment and all PR professionals should be aware of its importance.

\footnotetext{
* Corresponding author. Tel.: +34 629073230.

E-mail addresses: alfonso_gonzalez@es.ibm.com (G.-H. Alfonso), miguelruiz@es.ibm.com (R. de Valbuena Miguel).

1 Tel.: +34 913976061 .
} 
But, how are public relations and communications professionals facing this evolution? Several authors (Adams, 1999; Geibel, 1999; Gower \& Cho, 2001; Holtz, 1999; Porter \& Sallot, 2003) have indicated that many public relations teams are still ill-equipped to handle those changes, and suffer from "fear of technology" (Horton, 2004, p. 1) concluding that many corporate communications and public relations professionals are still behind schedule when it comes to Web use, that they should adapt their strategic vision to deal with this new reality, and that they need to understand online processes, beyond simple use.

Currently, e-mail systems provide a very useful media to send messages to an organization's different audiences in a variety of formats. However, it is Web pages that are showing the greatest progress, thanks to better design possibilities, integration of multimedia elements and greater interaction with the user.

These possibilities have not gone unnoticed by organizations, and, where media relations is concerned, many companies already devote specific sections of their Web to communicate with the media, usually called "online press rooms". From this specific area, companies can deliver any type of news to the press, making it easy for journalists to obtain information regarding the company, while simultaneously serving as a channel for information requests to the company and offering particular advantages for some organizations with limited resources to invest in costly marketing tools (Naudè, Froneman, \& Atwood, 2004).

In fact, agency professionals admit that facilitating media relations is the primary purpose for which they use the Internet on behalf of their clients (Gower \& Cho, 2001, p. 87), and a myriad of Internet software and services companies have developed e-business solutions for the public relations industry, enabling companies to create $24 \mathrm{~h}$ media relations centers.

However, only journalists have the last say about how corporations are meeting their demands for information and audiovisual resources. $70 \%$ of working journalists list the company website as the first stop when researching a breaking story or a feature (Magnet, 2002), similar to the number of journalists that think that the Internet has had the greatest impact on journalism in the past years (Brandsford, 2002, p. 6), or, simply, has made journalism better (The Pew Research Center, 2004, p. 4).

As practitioners, we tend to believe that our virtual press rooms provide the media with high-quality Internet materials, while — as Callison (2003) indicates— the same media often feel that corporate Web pages fail to deliver the information they are looking for.

Sometimes called "Net relations", "Webbed public relations", "Online PR", "Internet PR", ..., that is, the use of Internet tools and technologies in the communication process between organizations and their publics, is a subject of - still limited-but increasing attention by public relations professionals and scholars. Some studies (Esrock \& Leichty, 1999; Kent, Taylor, \& White, 2003; Krug \& Haselkorn, 2002) have analyzed the way in which these new corporate communications techniques and tools can be used from a theoretical standpoint. Others (Bovet, 1995; Ha \& Pratt, 2000; Kent, Taylor, \& White, 2001) have tried to establish the "state of the art" in the real use of such technologies. In several studies, the analysis that foresaw certain future trends in the use of these technologies referred to specific and limited geographic environments or countries (Ayish, 2005; Naudè et al., 2004) or to specific public relations disciplines such as the use of the Internet in crisis communications (Taylor \& Perry, 2005).

Comparatively, little international research has been conducted to assess practitioners' use of the Internet as a facilitator of media relations. Some studies in the United States, however, have analyzed in recent years the specific content of U.S. corporate Web pages related to the news media. In 1999 and 2000, Esrock and Leichty reported results of a-somewhat limited-content analysis study from a sample of 100 companies from the Fortune 500 ranking. Likewise, in 2003 Callison studied how corporations were using the Web to meet the information needs of journalists, conducting a content analysis of all the 2001 Fortune 500 U.S. Companies websites. More recently, Momorella and Woodall (2005) have reported additional results about some aspects of Fortune 500 online newsrooms.

Esrock and Leichty's studies $(1999,2000)$ focused on a sample of exclusively U.S. companies and on the analysis of a limited number of variables (press releases, contact information, etc.) wherever they could be found on the websites. Our research, however, increases the number of variables taken into account to 52 and analyzes primarily the content of the centralized areas within the corporate website dedicated to the media (virtual press rooms) in eight different countries worldwide: Denmark, France, Germany, Norway, Singapore, Spain, the United Kingdom and the United States.

Callison (2003) increased the number of variables included in the research to 38, and was the first author to investigate in such detail the use of press centers on the Web. Callison's research was certainly a solid step towards understanding the use of new technologies in interaction with the media but it was also totally U.S.-centric. 
These previous studies therefore seem to offer some limitations when extracting conclusions about global trends, since the Fortune Top 500 ranking, used by all of them in their samples and research, is limited to the largest U.S. companies.

\section{Objectives}

This study established two clearly defined objectives:

1. To explore the use of the Internet as a communications and relationship tool with the media by leading international companies from the U.S. and Europe.

2. To discover if common or differential parameters and current trends could be established among the different countries analyzed regarding the use of the Internet in the relationship between companies and the media.

With the goal of reaching these objectives, the research team analyzed Web pages from a selection of large European and U.S. companies - to which it was also added the case of Singapore—as a result of a short-list of technologically advanced countries.

\section{Method}

As a first step of the study, desk based research was conducted, confirming the limitations of the scarce international studies about the subject in existence to date. In parallel, a focus group with several representatives from the Spanish media was held to gather qualitative information about the use of virtual press rooms by the media. This information was used for the design of the questionnaire and the subsequent quantitative research.

Next, the countries and companies to be studied were defined. Specifically, 15 companies would be selected from those with the highest revenue in 6 European countries (Denmark, France, Germany, Norway, Spain and the United Kingdom), and from the U.S. and Singapore. That is, a total of 120 companies from 8 different countries.

The guide used to determine the selection of countries was the $e$-readiness ranking prepared every year by The Economist and IBM (The Economist Intelligence Unit, 2004), that analyzes the degree to which different countries around the world are receptive to the use of Internet technologies in diverse sectors (corporate, governmental, social, etc.).

Due to the predominance of the Nordic countries in terms of penetration and use of these technologies, it was considered appropriate to include two countries from this region in the study (Denmark and Norway, positioned first and fourth in the e-readiness ranking, respectively). The data from the league table seemed to indicate that companies in these two countries could be using more advanced professional practices.

The rest of the countries selected for the study included the United Kingdom (positioned second in the ranking), the United States (ranked 6th), Singapore (ranked 7th), Germany (ranked 13th), France (ranked 18th) and Spain (ranked $21 \mathrm{st}$ ). The inclusion of Germany and France was mainly due to the economic power held by the companies of these countries in both the European and global economy. The inclusion of Spain was due to the research team's interest in having specific data from this country.

Once the countries were determined, the companies to be analyzed were selected from the Fortune Global 500 ranking (2004), which includes the largest 500 companies from around the globe. In cases such as those of Denmark, Singapore and Spain it was necessary to refer to other publications (Actualidad Económica, 2003; Asiaweek.com, 2004; Dinero, 2001; Fomento de la Producción, 2003), since the Fortune Global 500 list did not include the minimum 15 companies from these countries required for the analysis.

After conducting a pre-test of the questionnaire among a small number of organizations, data gathering from the 120 companies selected for the study took place in August and September 2004. The final analysis of the data took place in January and February 2005, once the data collected were loaded into a SPSS file for processing.

\section{Results}

\subsection{Importance of media sections}

According to the results, the media are considered the second most important audience after clients. $87 \%$ of the Web sites analyzed had specific hyperlinks in their homepages targeting "customers", while almost $78 \%$ had hyperlinks 
to "media" specific sections, and $70 \%$ to "investors". This means an increase in relevance of the "media" sections if compared with Esrock and Leichty's (2000) content analysis, where media ranked fourth, after shareholders, prospective employees, and customers.

\subsection{Number of websites with press rooms}

This study has confirmed that today most large companies (92\%), have a specific website designed to meet the information needs of the media, which represents an important increase if compared to the 2001 results reported by Callison (2003). These results are consistent with the aforementioned opinion that media professionals are the second most important audience for corporate websites.

The most common denomination is "press room" (or its equivalent in different languages), even though there are also other similar terms used, such as "press center", "media center" or simply "media" or "press" exclusively referring to the audience they are aimed at.

\subsection{Number of clicks required to reach the press room}

Most of the press areas are found in a very visible and easily recognizable way from the corporate home page, making it unnecessary to carry out a complex search to find them, as $75 \%$ of them only need a single click to access this area (versus 62.6\% in Callison's 2003 study). This seems to be in line with a previously identified characteristic of a good virtual newsroom: it must be structured in a way that facilitates quick location, access, and retrieval of its information resources (Callison, 2003, p. 31; Settles, 1996, p. 12).

\subsection{User name and password}

The use of security elements - such as user name and/or password - to access the online press rooms, is clearly a minority phenomenon (5.4\%) in the companies analyzed, a trend that we believe responds to the needs and requests of the media to access corporate information immediately, quickly and easily. Neither Esrock and Leichty (2000), nor Callison (2003) reported results about this variable. Momorella and Woodall (2005) did report results for this variable in a recent study, indicating that $10 \%$ of Fortune 500 companies required registration in their press rooms.

Table 1 summarizes results of the number of companies with websites, online press rooms, number of clicks needed, and number of companies requiring previous registration. One of the main conclusions that could be drawn from these results - especially if compared with results from previous research-is that large companies, independently of their country of origin or industry sector, recognize not only the importance of having online tools for corporate communications, but also that these tools must be easily and directly accessible without any kind of obstacle for media professionals, even if password protection and registration facilitates tracking and reporting by PR practitioners.

\subsection{Written content included in press rooms}

One hundred percent of the companies analyzed in this study had press releases on their websites (compared to 96.9\% reported by Callison in 2003, and 88\% reported by Esrock \& Leichty in 1999). 83\% of those organized their

Table 1

Availability and access to the press rooms (overall results)

\begin{tabular}{|c|c|c|c|}
\hline Topics & & Yes $(\%)$ & No $(\%)$ \\
\hline Website $(N=120)$ & & 100.0 & 0.0 \\
\hline Press room $(N=120)$ & & 92.5 & 7.5 \\
\hline Is registration required? $(N=111)$ & & 5.4 & 94.6 \\
\hline Topics & 1 Click $(\%)$ & 2 Clicks (\%) & 3 Clicks $(\%)$ \\
\hline Number of clicks $(N=111)$ & 75.7 & 22.5 & 1.8 \\
\hline
\end{tabular}


press releases by date while $17 \%$ of companies classified their releases by topic. Since journalists usually work by subject or beat (and nor by date) that is how the newsroom should be structured (Breakout from IT, 2003).

By country, the best scores related to written information are those of the United States, where we can find all kinds of written materials. The abundance of press releases (100\%), reports (100\%), financial data (93\%), biographies (73.3\%), historical data $(46.7 \%)$, etc., is combined with good classification of information and correct location in the press rooms.

Denmark and Norway (with only $14.3 \%$ and $21.4 \%$, respectively, of press rooms providing backgrounders, and no biographies among the 30 companies analyzed in these 2 countries), France and Singapore (with $7.1 \%$ of press rooms with financial data available), and the UK and Singapore (with $0 \%$ providing historical information) represent the poorest results.

On average, by type of material, backgrounders (59.5\%), biographies (24\%), financial information (40.5\%) and historical data $(35.7 \%)$ are less common than press releases.

In qualitative terms, and in comparison to the results of the U.S. companies, the companies from the rest of the world do not always put the materials in the right place in their online press room or it is not classified correctly, something that, in certain cases, might mean that the journalists will not find the information sought.

Statistical tests show significant differences among the countries analyzed, regarding to the use of different kinds of written information. For example, in backgrounders $\left(\chi^{2}(14, N=111)=66.058, p=0.000\right)$ or biographies $\left(\chi^{2}\right.$ $(14, N=111)=68.573, p=0.000)$, some countries, e.g. the U.S., are quite well-positioned in comparison with other countries, like the Nordics or France.

\subsection{Image and graphic archives}

Previous research has indicated the importance of offering the media downloadable graphic resources in press rooms (Deloitte \& Touche, \& Acceso, 2002). In fact, a 2001 survey found that downloading images to use in stories was one of the top five reasons journalists visit company websites (Nielsen Norman Group, 2001).

In the German press rooms analyzed, the great importance given to photo archives stands out and they scored the best results (93\%) in this section, with most of the pictures in medium-high quality. At the opposite end of the scale, the U.S. (20\%) and France (29\%), have the worst results in this area.

Nonetheless, out of the total number of companies analyzed throughout the research, only $50 \%$ include a photo archive to be used by the media. A test statistic $\left(\chi^{2}(7, N=111)=23.298, p=0.002\right)$ shows that there are significant differences among countries. Although these are slightly better results than those of Callison's (2003) research (that showed only $48.7 \%$ of press rooms with executive photographs, and even worse figures for product pictures or logos), there is a great deal of progress to be made in this area.

In the entire group of countries, the results among the companies that have downloadable pictures and images are good in terms of quality or ease of use ( $84 \%$ of the companies offer preview versions). In other sections, such as the use of graphs, both charts and illustrations or logos, the results in general are very poor and there is room for improvement. A high number of companies analyzed (84\%) do not offer graphics for the media yet, although there are significant differences among countries, according to statistical tests $\left(\chi^{2}(21, N=55)=67.686, p=0.000\right)$.

\subsection{Multimedia resources (audio and video)}

In the analysis of the use of audiovisual tools in the virtual press rooms, this study reveals a growing area, but one that does not yet make full use of the potential technology offers. This study has not found a single example of a high-quality video that could be used by television broadcasters and available to be downloaded from the press rooms. Thus, broadcast-quality video seems to be a resource that if not impossible, is at least very complicated to include on websites, because of the size of the files. Nevertheless, this does not explain the scarce availability of low quality videos (11\%), which could be viewed by television professionals prior to ordering higher-quality copies or by any kind of media professional, just to expand on information.

In terms of the inclusion of audio files on the websites, with statements or speeches from company spokespeople, this is also a resource clearly under-used by the companies analyzed. Only 7 out of 100 companies offered this kind of material. The possible causes of this low use might be due to certain corporate strategies or communication policies or, simply, to the lack of proactivity of certain communications departments, more than in the technical requirements of the process. 
Table 2

Main content in press rooms (overall results)

\begin{tabular}{|c|c|c|c|c|}
\hline Topics & Yes $(\%)$ & No $(\%)$ & Outside $(\%)$ & $\chi^{2}$ \\
\hline Press releases & 100.0 & 0.0 & 0.0 & $\chi^{2}(7, N=111)=6.992, p=0.430$ \\
\hline Backgrounders & 59.5 & 34.2 & 6.3 & $\chi^{2}(14, N=111)=66.058, p=0.000$ \\
\hline Biographies & 24.3 & 59.5 & 16.2 & $\chi^{2}(14, N=111)=68.573, p=0.000$ \\
\hline History & 23.4 & 49.5 & 27.0 & $\chi^{2}(14, N=111)=53.445, p=0.000$ \\
\hline Financial data & 35.1 & 40.5 & 24.3 & $\chi^{2}(14, N=111)=73.922, p=0.000$ \\
\hline Press clips & 18.0 & 68.5 & 13.5 & $\chi^{2}(14, N=111)=29.288, p=0.010$ \\
\hline Photo archive & 49.5 & 50.5 & 0.0 & $\chi^{2}(7, N=111)=23.298, p=0.002$ \\
\hline Video archive & 10.8 & 89.2 & 0.0 & $\chi^{2}(7, N=111)=7.584, p=0.371$ \\
\hline Audio archive & 7.2 & 92.8 & 0.0 & $\chi^{2}(7, N=111)=12.846, p=0.076$ \\
\hline
\end{tabular}

Research reveals therefore that there is still a lot of room for improvement, regarding multimedia resources in international press sites.

It should be noted that the German press rooms show the highest percentages in the use of audiovisual resources ( $28 \%$ in both segments). At the opposite end of the scale, in the press rooms of French companies analyzed we did not find any type of audiovisual resource (Table 2).

\subsection{Interactivity and responsiveness}

Interactivity is one of the key elements when talking about new technologies and the Internet. Several studies (Esrock \& Leichty, 1998; Kent et al., 2003; Naudè et al., 2004) have pointed out how corporate websites provide a challenging opportunity for organizations to cultivate a beneficial dialogue with its different publics.

Most of these authors have tried to see the application of Grunig and Hunt's (1984) two-way symmetrical model by measuring how organizations were using interactive tools to build a constructive relationship with their publics, since it is widely accepted among scholars (Naudè et al., 2004) that the technical characteristics of the Web make it possible to apply the model to the practice of online public relations.

This study confirms findings from previous research, concluding that corporations neither make use of the full potential of the Internet nor do they use the interactive features it provides today efficiently.

The most common shortfall in all the companies analyzed, regardless of their geographic location, is the lack of value given to website interactivity. Although they pass the easy test of offering means of contacting the communications department (almost 86\% versus Callison's 2003 figure of 68\%, and 60\% in the 1999 Esrock and Leichty study), this study tried to verify if those contact channels, be it via e-mail or via a request form on the Web, were as efficient as the traditional ones (via telephone or personal contact). For that purpose, a member of the research team sent a simple question to all the PR departments which offered an e-mail or request form.

The results were significant: up to $70 \%$ of queries made were not answered by the companies analyzed. The lack of responses to the requests made through the Web, together with the general delay in the few responses received (two out of three companies that answered the e-mail query did it in 3 or more days), indicates that in many cases this contact method is not a priority, but rather a channel that has been semi-abandoned by the companies themselves. In this way, the possibility that the media engages in dialogue is forgotten and with it, a key dimension of interactivity, reciprocal communication (Ha \& James, 1998).

With the results of this study, it is clear that there is a serious problem that might diminish the reliability and efficiency of the press room as a corporate communications tool.

Moreover, the scarce number of companies that offer additional information, contact and loyalty tools (alerts, online interviews or newsletters) reflects that in the realm of interactivity between a company and the media there is still a lot to be done in order to take advantage of the full potential of the Internet as a corporate communications tool.

\subsection{RSS feeds}

Really Simple Syndication (RSS) is an expanding technology among online media and emerging blogs. Organizations should also consider offering RSS feeds within their virtual press rooms, since e-mail is an increasingly 
Table 3

RSS feeds in press rooms

\begin{tabular}{lrr}
\hline Countries & Yes $(\%)$ & No $(\%)$ \\
\hline Denmark & 14.3 & 85.7 \\
France & 7.1 & 92.9 \\
Germany & 21.4 & 78.6 \\
Norway & 0.0 & 100.0 \\
Singapore & 0.0 & 100.0 \\
Spain & 8.3 & 91.7 \\
UK & 7.1 & 92.9 \\
USA & 13.3 & 86.7 \\
All countries & 9.0 & 91.0 \\
\hline
\end{tabular}

$\chi^{2}(7, N=111)=6.350, p=0.500$.

problematic communication tool due to the growth of spam and the overwhelming number of e-mails many journalists receive. RSS offers an alternative way to receive information-such as press releases-by subscription.

Only $9 \%$ of the 120 companies analyzed in this study are offering this kind of service in their press rooms (results that were updated in December 2005 by the research team). Even with the exception of Germany (21\%), Denmark (14\%), or the U.S. (13\%), such low percentages in rest of the countries may confirm that the application of new emerging tools in public relations processes are still one step behind the real use of those technologies in other areas of society (Table 3).

\subsection{Authorship and content updates}

The development of cold and impersonal automated press rooms, might result in the low confidence journalists place in them when, for instance, they need to ask for further information or identify the authors or specialists of the information to make further requests. This study shows that only $25 \%$ of the press rooms identify the authors of the releases or other information, in what constitutes a generalized shortfall, with the sole exception of the United States and the United Kingdom, with percentages above 50\%. At the other end of the scale, none of German, French or Norwegian companies showed any contact information. These relevant differences among countries are confirmed by the statistical test $\left(\chi^{2}(7, N=111)=43.196, p=0.000\right)$.

The updating of content, another aspect highly valued by the media, also showed negative results in this study. With the exception of the United Kingdom (57\%) and Germany (50\%), daily or immediate updating of information is not common in press rooms. Only $39.6 \%$ of companies analyzed updated their press rooms' contents on a daily basis.

In certain cases, this could be conditioned by the type of company and by the volume of corporate information transmitted externally. Even so, it seems obvious that the media will pay more attention to press rooms that update their content almost immediately, so that neglecting this aspect might have a serious effect on the usefulness of the press room as a communications tool, and as a loyalty factor, for media professionals.

Hill and White (2000) found that traditionally practitioners had lacked additional resources to maintain their websites. Also, Ayish (2005, p. 387) suggests how, in certain countries, public relations professionals are not directly involved in the updating of the organization's site. However, the media demand that press rooms are built and updated by professionals, who know and respond to their needs and information requests. Momorella and Woodall (2005, p. 22) showed that journalists considered the ability to access professional contact data as essential.

\section{Conclusion}

The global economic environment and the fast replication of corporate practices in online environments might explain the fact that there is no country that significantly stands out from the rest. In fact, a common feature in most of the press rooms analyzed is that good results in certain areas coexist with important shortcomings in other areas. Even then, some partial data might be extracted, like, for instance, the abundance of resources and the best practices of U.S. companies in terms of written documents or the importance given by German companies to the graphic contents in their press rooms. 
The analysis of the results obtained by the Nordic countries (Norway and Denmark) is also of great interest for this study, since these countries are usually considered models of the penetration of new technologies in social and business realms. Their e-readiness ranking confirms as much. However, this research appears to demonstrate that the global technological level of a country does not always go hand in hand with the application and exploitation of technology in certain spheres and, specifically, in the sphere of corporate communications. Thus, companies in the Nordic countries show noteworthy weaknesses, not only for the lack of resources (reports, biographies, financial data, history), but also for the poor organization and classification of certain sections.

The geographic factor is not the only deciding factor of the common or differential aspects that have been observed among the companies analyzed in this study. There are other factors such as the size of the companies (in terms of revenue and human resources), whether they are multinational or local, to which industry sector they belong, etc. that also determine to a great extent the adoption and development of their virtual press rooms. For this reason, it would be interesting to be able to compare in the future the results of the present study-which, by design and objectives, has focused on the main companies of each country, disregarding other variables-with data that could allow for a comparison by industry sector, local or multinational presence, or lower revenue levels.

For example, the study shows some data—insufficient to be conclusive though — that points to the fact that some sectors are more advanced than others in the use of these tools. There also appear to be data indicating that the development of press rooms correlates with the availability of resources for their development and maintenance. If proven to be true, this would mean that companies of a smaller size would have less sophisticated tools. Further studies could deepen this insight into these aspects.

Furthermore, it is obvious that this study only shows one side of the virtual relationship between companies and the media. That is, the research has analyzed how corporate organizations structure their information channels and their online interaction with the media, but it has not analyzed how the international media are using these tools. There is no doubt that a study into this aspect would deliver interesting information to complement this research effort.

\section{A final note}

This article has shown that the use of Internet tools to build strong and solid relationships with the media is far from ideal.

Even when the Internet is a complement to, not a replacement for, other existing methods of communication, this content analysis provides quantitative measures of how companies and organizations are not taking full advantage of these resources. Furthermore while media professionals and journalists are increasingly relying on the Net to write their reports, most companies do not understand the benefits of, not only providing information, but also organizing and updating it on a daily basis. The overall results show how there is a lot of room for improvement in areas such as written information, content updates or identification of authors.

The very power of the Internet also magnifies the weaknesses in an organization's public relations practice. Consequently certain results from this study seriously put at risk the image of some organizations' press rooms as efficient, valuable and reliable tools.

Fulfilling media relations objectives through the world wide Web requires well-defined communication strategies before the implementation of a virtual press room. And, in many of the companies analyzed in this study, the significant shortcomings detected may reflect that these companies do not have a comprehensive, well-designed strategy in this area and/or enough resources to execute it. They have a long way ahead to improve.

\section{References}

Actualidad Económica (Ed.). (October 2003). Las 5.000 mayores empresas [The largest 5,000 corporations]. Madrid, Spain: Author.

Adams, B. (1999). Ask the professor. Public Relations Tactics, (November), 3.

Asiaweek.com. (2004). Top 1000. Companies by country: Singapore, Retrieved June 10, 2004, from website: http://cgi.cnn.com/ASIANOW/ asiaweek/features//asiaweek1000.2000/c_singapore.html.

Ayish, M. I. (2005). Virtual public relations in the United Arab Emirates: A case study of 20 UAE organization's use of the Internet. Public Relations Review, 31, 381-388.

Bovet, S. (1995). 38\% of Canadian journalists use Internet, survey shows. Public Relations Journal, 51(8), 54-55.

Brandsford, K. (2002). Better, smarter Internet media relations. Public Relations Tactics, 9(7), 6.

Breakout from the IT Mold to Make Online Newsrooms Bolder. (2003). PR News, 45(November), 1. 
Callison, C. (2003). Media relations and the Internet: How Fortune 500 company Web sites assist journalists in news gathering. Public Relations Review, 29, 29-41.

Deloitte \& Touche, \& Acceso (Eds.). (2002). Estudio sobre el uso de la Red en medios de comunicación [Research about the use of the Net in mass media]. Madrid, Spain: Author.

Dinero. (2001). Ranking empresarial de empresas europeas [Business ranking of European companies], Retrieved June 15, 2004, from website: http://www.negocios.com/dinero/ranking/.

Esrock, S. L., \& Leichty, G. (1998). Social responsibility and corporate Web page: Self presentation or agenda setting? Public Relations Review, 24, 305-319.

Esrock, S. L., \& Leichty, G. (1999). Corporate World Wide Web pages: Serving the news media and other publics. Journalism and Mass Comunications Quarterly, 76, 456-467.

Esrock, S. L., \& Leichty, G. (2000). Organization of corporate Web pages: Publics and functions. Public Relations Review, $27,327-344$.

Fomento de la Producción (Ed.). (2003). Las 2000 mayores empresas españolas [The largest 2000 Spanish corporations]. Barcelona, Spain: Author.

Fortune Global 500 (2004). Retrieved July 20, 2004, from Fortune Magazine website: http://www.fortune.com/fortune/subs/pdf/072604/2004_ global500.pdf.

Geibel, J. P. (1999). How digital tools and audiences are changing high-tech PR. Public Relations Tactics, 5(November), 18.

Gower, K., \& Cho, J. Y. (2001). Use of the Internet in the public relations curriculum. Journalism and Mass Communication Educator, 56(Summer (2)), 81-92.

Grunig, J. E., \& Hunt, T. (1984). Managing public relations. New York: Holt, Rinehart \& Winston.

Ha, L., \& James, E. L. (1998). Interactivity reexamined: A baseline analysis of early business web sites. Journal of Broadcasting and Electronic Media, 42(4), 457-474.

Ha, L., \& Pratt, C. (2000). The real state of public relations on the World Wide Web. Public Relations Strategist, 6(3), 30-33.

Hill, L. N., \& White, C. (2000). Public relations practitioner's perceptions of the World Wide Web as a Communications Tool. Public Relations Review, 26, 31-51.

Holtz, S. (1999). Public relations on the Net. New York: AMACOM.

Horton, J. L. (2004). Learning Online Crafts, Retrieved December 28, 2005, from Online Public Relations Website: http://www.onlinepr.com/Holding/LearningOnlineCrafts.pdf.

Kent, M. L., Taylor, M., \& White, W. J. (2001). How activist organizations are using the Internet to build relationships. Public Relations Review, 27, 263-284.

Kent, M. L., Taylor, M., \& White, W. J. (2003). The relationship between Web site design and organizational responsiveness to stateholders. Public Relations Review, 29(1), 63-77.

Krug, M. A., \& Haselkorn, M. P. (2002). Aligning Web information policy with strategic organizational goals: Preliminary case study findings. Reflections on Communication, 360-363.

Magnet. (2002). Ninth Annual Middleburg/Ross Survey of Media Professionals, Retrieved January 14, 2006, from American Marketing Association: http://www.marketingpower.com/content25753.php.

Momorella, S., \& Woodall, I. (May ,2005). Evolution at work: Survey shows the structure of Fortune 500 online newsrooms. Public Relations Tactics, 12(5), 27.

Naudè, A. M. E., Froneman, J. D., \& Atwood, R. A. (2004). The use of the Internet by ten South African non-governmental organizations: A public relations perspective. Public Relations Review, 30, 87-94.

Nielsen Norman Group. (2001). Designing Websites to Maximize Press Relations, Retrieved January 17, 2006, from: http://www.nngroup. com/reports/pr/summary.html.

Porter, L. V., \& Sallot, L. M. (2003). The Internet and public relations: Investigating practitioners' roles and World Wide Web use. Journalism and Mass Communications Quarterly, 80(Autumn (3)), 603-622.

Settles, C. (1996). How to build a press center on the Web. Public Relations Tactics, (November), 12.

Taylor, M., \& Perry, D. (2005). Diffusion of traditional and new media tactics in crisis communication. Public Relations Review, 31, $209-217$.

The Economist Intelligence Unit \& IBM Institute for Business Value. (2004). The 2004 e-readiness ranking, (April), Retrieved July 25, 2005, from http://www-5.ibm.com/dk/news/pressepdf/e_ready04_full_report.pdf.

The Pew Research Center. (2004). How Journalists See Journalists in 2004, Retrieved January 16, 2006, from: http://peoplepress.org/reports/pdf/214.pdf. 